\title{
Perceptions of Psychosocial Hazards, Work-related Stress and Workplace Priority Risks in Developing Countries
}

\author{
Evelyn Kortum, Stavroula LeKa and Tom Cox \\ Institute of Work, Health and Organisations, University of Nottingham, UK
}

\begin{abstract}
Perceptions of Psychosocial Hazards, Work-related Stress and Workplace Priority Risks in Developing Countries: Evelyn Kortum, et al. Institute of Work, Health and Organisations, University of Nottingham, UK-Objectives: During the last few decades, major global developments in the world of work include an international trend to shift production to developing countries, with wide variations in working conditions and exposure to traditional and emerging occupational risks, such as psychosocial risks. The latter have rarely been addressed or explored in developing and economically-emerging country contexts while we find an abundant body of research from industrialized countries. The research presented, which is part of a larger study, explored the perception of multidisciplinary experts from different regions, as defined by the World Health Organization (WHO), of the nature of psychosocial hazards, and work-related stress, as well as their views on workplace priorities that require urgent attention. Methods: Semi-structured interviews were conducted with 29 experts from developing countries which were subjected to thematic analysis. A two-tiered Delphi survey was completed by 74 experts in the first round with 53 of these experts completing the survey in the second round. Results: Psychosocial hazards and work-related stress were mostly seen as interchangeable in terms of source and effect and all participants perceived them as concern to their workforce. Through the interviews and the Delphi surveys they allude to our contemporary understanding of psychosocial risks. Workplace risks of priority differed by region but primarily work-related stress, injury and accident prevention, and substance abuse and risk behaviors were reported to require urgent attention. Conclusions: The current lack of awareness and research in the area of psychosocial risks and work-
\end{abstract}

Received May 11, 2010; Accepted Jan 15, 2011

Published online in J-STAGE Feb 11, 2011

Correspondence to: E. Kortum, Institute of Work, Health and Organisations, University of Nottingham, Level B, International House, Jubilee Campus, Wollaton Road, Nottingham NG8 1BB, UK (e-mail:lwxek1@nottingham.ac.uk) related stress hampers action in developing countries. International experts should support the exchange of information and the development of interventions in workplaces in developing countries with a view to integrating these emerging risks into comprehensive occupational health and safety policy frameworks to make such approaches more effective.

(J Occup Health 2011; 53: 144-155)

Key words: Developing countries, Psychosocial hazards, Work-related stress

Developments at global level are marked by an intensification of the processes of interaction involving travel, trade, migration and dissemination of knowledge. These have shaped the progress of the world over millennia ${ }^{1)}$, and have introduced a shift towards more insecure forms of employment, reduced control in trade, reduction in public spending in real wages, and problems of reduced regulation and lack of enforcement of regulation on working conditions. Overall, recent data suggests that faster industrialization, urbanization and outsourcing, with a great increase in construction, and agricultural mechanization in developing countries has led to a rise in the number of workers exposed to traditional (for example, heavy physical workload) and new occupational risk factors $^{2)}$. Working conditions and the physical and psychosocial hazards they may pose, therefore, have the potential to affect workers' health also in developing countries. Although we currently lack research data, the changing nature of work and the impact of globalization increase the importance of addressing psychosocial risk factors and work-related stress in developing countries ${ }^{3)}$.

It is essential to keep the developing countries in our sight, considering that approximately $80 \%$ of the global workforce resides in the developing world ${ }^{4}$. Approximately $30-50 \%$ of workers report hazardous physical, chemical or biological exposures or overload of unreasonably heavy physical work or ergonomic factors that may be hazardous to health and to working capacity; an equal number of working people report psychological overload at work 
Table 1. Psychosocial risk factors

(adapted from: Work Organization and Stress, PWH series no. 3. 2005)

Organizational and workplace level

Work content:

Job content: Monotonous, under-stimulating, meaningless tasks; lack of variety; unpleasant tasks

Workload and work pace: Having too much or too little to do; working under time pressures

Working hours: Strict and inflexible working schedules; long and unsocial hours; unpredictable working hours; badly designed shift systems

Participation and control: Lack of participation in decision making; lack of control (for example, over work methods, pace, hours, environment)

Work context:

Career development, status and pay: Job insecurity; lack of promotion prospects; under-promotion or over-promotion; work of 'low social value'; piece rate payments schemes; unclear or unfair performance evaluation systems; being over-skilled or underskilled for the job

Role in the organisation: Unclear role; conflicting roles within the same job; responsibility for people; continuously dealing with other people and their problems

Interpersonal relationships: Inadequate, inconsiderate or unsupportive supervision; poor relationships with co-workers; bullying, harassment and violence (incl. sexual harassment); isolated or solitary work; no agreed procedures for dealing with problems or complaints

Organisational culture: Poor communication; poor leadership (including downsizing); lack of clarity about organisational objectives and structure

Home-work interface: Conflicting demands of work and home; lack of support for domestic problems at work; lack of support for work problems at home

Physical work environment: Unsafe procedures; no or limited information available to protect oneself; risk of injury or death

Employment conditions: Precarious jobs; job insecurity

resulting in stress symptoms ${ }^{5}$. Psychological overload is caused by psychosocial risk factors. There is considerable evidence, and reasonable consensus, within the research community of industrialized countries of work aspects which are experienced as stressful and/or have the potential to harm ${ }^{6}$ ) Table 1 gives a comprehensive account of contemporary psychosocial risk factors as defined by industrialized country experts.

Recent studies indicate that contemporary and emerging psychosocial risks are changing and go beyond the traditional workplace-centered approach. These include external factors such as globalization ${ }^{7)}$, increased vulnerability of workers in the context of globalization, precarious contracts in the context of the unstable labor markets, new forms of employment contracts, and the feeling of job insecurity ${ }^{8}$. Psychosocial hazards have previously been described as an integral element of the stress process, in terms of the interaction among job content, work organization and management, environmental and organizational conditions on the one hand, and the employees competencies and needs on the other; an interaction that can prove to be hazardous to employees' health through their perceptions and experience ${ }^{9}$.

The global definition of work-related stress underlines that the most stressful type of work is that which values excessive demands and pressures that are not matched to the worker's knowledge and abilities, where there is little opportunity to exercise any choice or control, and where there is little support from others ${ }^{10)}$. This view is based on contemporary theories, such as the job-demand-controlsupport theory ${ }^{11)}$, and the effort-reward imbalance model ${ }^{12)}$. A meta analysis (2004-2005) suggested that particularly combinations of high demands and low decision latitudes as well as high effort and low rewards are associated with psychological disorders, such as depression and anxiety ${ }^{13)}$. Furthermore, the effort-reward-imbalance model could be associated with cardiovascular disease, poor self-perceived health, and several mental disorders ${ }^{14)}$. Therefore, the psychosocial work environment has an impact on workers' health.

Some positive developments have been taking place, for example, in Latin America, where awareness about the importance of psychosocial risks and their impacts has been increasing recently. Research shows an increase in studies that deal with psychosocial risks each year, reaching up to $25 \%$ of all studies in occupational health presented in 2006. Burnout studies in service occupations are the most common type of investigation and between $16-30 \%$ of prevalence has been reported and associated with various psychosocial aspects of work. For example, high job strain in $24 \%$ of workers was reported in studies conducted in Argentina and Mexico ${ }^{15}$. 
On the African continent, the First Inter-ministerial Conference on Health and Environment recognized in its report that "Africa not only has to cope with traditional environmental risk factors to human health, it now also has to cope with new and emerging threats, including new occupational risks". These are explained to add to the burden of traditional occupational health problems such as injury, respiratory disorders, dermatitis and musculoskeletal problems. The report further states that "Africans are now suffering from asthmatic conditions and psychosocial stress"16). The African report neither eludes any further to psychosocial risks, nor does it indicate how to tackle this emerging risk. However, the recognition of psychosocial risk as an issue that requires addressing is a first step towards future action.

Workers around the world, despite differences in their environments, face practically the same types of workplace hazards in terms of chemical, biological, physical and psychosocial $^{4}$. This part of the study aimed at addressing part of the knowledge gap in developing countries by exploring the perceptions of experts and their knowledge of the nature of psychosocial hazards and their understanding of workplace risks that require urgent attention. Eventually it will be such experts who will deliver research evidence and provide the basis for policy developments in their countries.

\section{Methods}

\section{Identifying and recruiting participants}

Experts familiar with issues concerning the psychosocial work environment and work-related stress in developing countries, were identified via existing occupational health networks of multi-disciplinary experts. Participants completed an online registration form. Criteria for inclusion were: (a) expertise in a field related to occupational health; psychology, sociology, epidemiology, medicine, psychiatry, etc.; (b) number of years of experience in their respective field; (c) basic knowledge on workplace interventions for psychosocial risks at work; and (d) a degree of practical experience in the application of methods or interventions that concern psychosocial risks at work. 79 participants from across all global regions were recruited to collect a suitable breadth of data, and yield a holistic representation of the developing world context including the six world regions as defined by the World Health Organization.

\section{Procedure}

The study used a mixed methodology combining qualitative (semi-structured interviews) and quantitative (Delphi survey) research methods. The first stage of the study used semi-structured expert interviews. For example, Miles and Huberman (1994) indicate that qualitative research lives and breathes through the context provided and that it is the particularities that produce the generalities, not the reverse ${ }^{17)}$. The interview findings were thematically analyzed and were used to develop an online Delphi survey that was completed by experts in two rounds.

The Delphi technique has previously been used to determine if there are emerging patterns or consensus on particular issues and it is a method for the "systematic solicitation and collation of judgments interspersed with summarized information and feedback of opinions derived from earlier responses"18). Later research confirmed that the Delphi is a structured group interaction process that is directed in rounds of opinion collection, which is achieved by conducting a series of surveys using questionnaires ${ }^{19}$. Because the study involves experts, it is assumed that some reasonable quality information will be obtained, and because it is an iterative system, it is assumed that good quality knowledge will evolve.

\section{Semi-structured expert interviews}

The interview schedule was developed based on a scientific literature review and included ten questions in total. This paper presents key findings in relation to three questions which, a) explored respondents' understanding and conceptualization of work-related stress, and b) psychosocial hazards; and c) assessed the level of concern attributed to these issues within the context of the developing world. 29 multi-disciplinary individuals from those previously recruited were interviewed. Following the selection of participants, e-mails were sent proposing a date and time for a telephone interview. After pilot runs and adjustments, the questions were forwarded to participants prior to the interview since this would be conducted in English, a second or even third language to most participants, thus allowing sufficient time for preparation. Table 2 outlines the countries represented by the participants and their backgrounds.

Data gathered was summarized and transcribed. Thematic analysis was applied to analyze the data ${ }^{20)}$. Emerging themes were identified across all regions. Interview transcripts were reviewed in detail to familiarize the research team to their content and then develop a set of "open codes", specifically, summarizing the content of short sections of the text in a few words. Transcripts were read repeatedly to identify the key themes and categories for coding. The collection of generated open codes were discussed and reflected upon by the research team, and subsequently grouped into broader categories established by consensus. The collection of categories was used to develop the initial coding frame, which was used to identify emergent themes. The template was viewed as a continuously evolving template and where information was found not to fit into the existing framework, the template was further refined and developed. Theoretical saturation was achieved once the final coding frame was developed and all relevant first- and second-order themes 
Table 2. Interview participant demographics (Participant distribution -29 expert interviews)

\begin{tabular}{|c|c|c|}
\hline Global region $^{1}$ & No. & Countries discussed and participants' disciplines \\
\hline Africa & 8 & $\begin{array}{l}\text { Namibia }(4)^{2} \text { : Social work, academia; psychology \& medicine; medicine, } \\
\text { HIV/AIDS focus and advocacy in public health } \\
\text { Nigeria: Psychology (lecturer) } \\
\text { South Africa (2): Epidemiology; OHS }{ }^{3} \text { expert } \\
\text { Zambia: Industrial psychology, leadership \& organization development }\end{array}$ \\
\hline Americas & 5 & $\begin{array}{l}\text { Trinidad and Tobago: Management and human resources } \\
\text { Chile: Epidemiology, medicine and psychiatry } \\
\text { Colombia: Psychology, epidemiological surveillance and research in links between } \\
\text { occupational diseases \& stress } \\
\text { Mexico: OHS expert } \\
\text { Puerto Rico: Psychology }\end{array}$ \\
\hline Eastern-mediterranean & 5 & $\begin{array}{l}\text { Iran (3): Psychology \& } \mathrm{OH}^{4} \text {; OHS expert; OH expert } \\
\text { Tunisia: Psychology, Epidemiology, Medicine } \\
\text { Pakistan: OH Physician }\end{array}$ \\
\hline Europe & 2 & $\begin{array}{l}\text { Albania: OH \& Epidemiology } \\
\text { Macedonia: Neuropsychological medicine }\end{array}$ \\
\hline South-east asia & 6 & $\begin{array}{l}\text { India (3): Sociology \& Psychology; Psychology \& Psychiatry } \\
\text { Malaysia: OHS expert } \\
\text { Thailand (2): Epidemiology; Epidemiology \& OH }\end{array}$ \\
\hline Western-pacific & 3 & $\begin{array}{l}\text { China: OH Physician } \\
\text { Federated State of Micronesia: Psychology, Psychiatry \& Medicine } \\
\text { Vietnam: } \mathrm{OEH}^{5} \text {; psychology and ergonomics }\end{array}$ \\
\hline
\end{tabular}

${ }^{1}$ According to the WHO Global regions. ${ }^{2}$ Number of participants from each respective country, indicated if more than one. ${ }^{3} \mathrm{OHS}=$ Occupational Health and Safety. ${ }^{4} \mathrm{OH}=$ Occupational Health. ${ }^{5} \mathrm{OEH}=$ Occupational and Environmental Health.

were identified.

To ensure inter-rater reliability for the interviews, three other researchers reviewed the collected emergent themes, and the coded data. Consensus was reached through discussion. Once patterns, associations, concepts, and explanations in the data were searched, and the new table established, an independent researcher examined the relationship between these occurring across the data set. Discrepancies in coding and themes were discussed and addressed in the final thematic table. The thematic grid that was produced was subsequently used to develop the Delphi survey.

\section{Delphi survey}

An e-mail message explaining the purpose and providing an overview of the study was sent to all previously recruited experts providing a link to the first online Delphi questionnaire, which requested demographic and background information, and contained questions discussed here that cover understanding of psychosocial risks and the most important workplace issues that require urgent attention in developing countries. Respondents were asked to rank their answers in the order of most important to least important. 74 individuals responded to the first online survey. Participants covered multiple areas of expertise from the areas of psychiatry, social work, medicine, epidemiology, sociology, ergonomics, but the largest number had expertise in occupational health and psychology. The data collected through the first Delphi survey was analyzed using frequencies (counting of responses) to identify highest consensus among experts. The ten top responses for each question were retained for the second round of the Delphi. A total of 53 experts of those that responded to the first round, also responded to the second round of the survey. Table 3 outlines the participant demographics and professional background. The experts' responses were again analyzed using frequencies to explore issues of highest consensus.

\section{Results}

Key findings from the interview questions probing the understanding work-related stress and psychosocial hazards and if these are of concern in participants' respective countries are presented in Table 4. Figure 1 from the Delphi survey provides regional answers with respect to psychosocial hazards. Figure 2 outlines experts' opinions on the workplace issues and risks that should most urgently be addressed in their countries. 
Table 3. Delphi participants

\begin{tabular}{|c|c|c|}
\hline \multirow[t]{2}{*}{ Primary region ${ }^{6}$} & AF-147; AM-22; EM-9; EU-53; SEA- & Professional background ${ }^{10}$ \\
\hline & 14; WP-15; Total: $127\left(74^{8}+53^{9}\right)$ & $\begin{array}{l}\text { Psychiatry, Social work, Medicine, Psychology, } \\
\text { Epidemiology, Occupational health, Sociology, } \\
\text { Ergonomics }\end{array}$ \\
\hline & & Others less represented: \\
\hline $\begin{array}{l}\text { Secondary region }{ }^{11} \text {, } \\
\text { if indicated }\end{array}$ & $\begin{array}{l}\text { AF-17; AM-23; EM-10; EU-49; SEA- } \\
\text { 16; WP-12; Total: } 127 \text { (74 \& 53) }\end{array}$ & $\begin{array}{l}\text { environmental management; OH\&S (hazard identification/ } \\
\text { risk assessment); HR development \& organization } \\
\text { development; work-organizational psychology; } \\
\text { environmental health, OH psychology; anthropology and } \\
\text { development; organizational behavior/HR management; } \\
\text { OH\&S; social epidemiology; health/social psychology; } \\
\text { work physiology, occ medicine }\end{array}$ \\
\hline
\end{tabular}

Developing countries Angola, Botswana, Burkina Faso, Ghana, Kenya, Namibia, Nigeria, South Africa, Uganda, Zimbabwe, concerned Chile, Colombia, Haiti, Mexico, Panama, Afghanistan, Egypt, Iran (Islamic Republic of), Pakistan, Tunisia, Albania, Kyrgyzstan, Turkey, India, Indonesia, Nepal, Sri Lanka, Thailand, China, Malaysia, Micronesia (Federated States of), Viet Nam

$\mathrm{OH}=$ Occupational Health, OH\&S.=Occupational Health and Safety

${ }^{6}$ Country/or region of origin or best known country. ${ }^{7}$ Number of participants from each region. ${ }^{8}$ This refers to the first Delphi survey round. ${ }^{9}$ This refers to the second Delphi survey round. ${ }^{10}$ The Delphi survey provided the possibility for several choices. ${ }^{11}$ If the primary region or country was not a developing country, respondents indicated a secondary developing country.

\section{Expert interviews}

The concepts of work-related stress and psychosocial hazards were perceived to be interchangeable by participants who did not make significant distinctions between the two concepts. They did, however, provide more information for psychosocial hazards than for workrelated stress for all categories, and work-related stress was more brought up mostly in connection with adverse health outcomes. For example, one African participant mentioned that for her "work-related stress and psychosocial hazards are combined. Stress is a body response, there is an external and an internal stimulus...people are unable to control the situation, the work content, the work organization, conflicting roles, and so on".

The main themes identified were (a) work organization, including issues of control and demand, work design, and work-home interface; (b) work schedule to include issues of working time; (c) workplace safety and hazards to include physical and psychological hazards and working environments of poor characteristics; (d) relationships that include psychological and physical violence, interpersonal conflict and lack of support; (e) socio-economic conflict and conditions to include issues of war, crime, poverty, HIV/AIDS, job insecurity and precariousness of jobs that go far beyond those we know from industrialized countries, existing and changing structures in the social, political economic and cultural spheres, as well as issues of globalization.

For example, one participant from the African region said "some work can be more stressful than other work. Quality of work decreases because often one person needs to carry the load of others, assume the work on top of their own work. This is particularly the case with HIV/AIDS patients who have high absence rates." With respect to the question, if these issues are of concern to workers' health, all participants responded that psychosocial hazards are of concern and mentioned the issues identified above in that context. For example, the Malaysian participant explained: "Yes, the issue of stress is high. First hazards are there. Second, they are higher in developing countries, in terms of cost, the work, stress is high."

\section{DELPHI findings}

Below, the most important results are presented from the Fig. 1 and 2 for the ten most commonly understood identified psychosocial risks (Fig. 1) and the workplace issues and risks that require urgent attention (Fig. 2).

Psychosocial risks include:

- Lack of control over work processes: By far participants from Africa (100\%) and the Americas (100\%) felt that psychosocial risks are understood in terms of lack of control over work processes. This understanding is followed by South-East Asian and Western Pacific participants to a lesser extent.

- Time Pressure and high job demands were preliminarily psychosocial risks for the Americas followed by the Western-Pacific, and to a lesser extent by the other, 
Table 4. Main themes obtained from participants of their understanding of work-related stress and psychosocial hazards, and the level of concern attributed to these issues within the context of the developing world

\begin{tabular}{|c|c|c|}
\hline Theme & Descriptor & Selected examples \\
\hline \multirow[t]{4}{*}{$\begin{array}{l}\text { Work } \\
\text { organization }\end{array}$} & Job control & $\begin{array}{l}\text { Control over work South Africa } \\
\text { People are unable to control the situation. Namibia }\end{array}$ \\
\hline & Work design & $\begin{array}{l}\text { Harm on the individual in the workplace, e.g. work design Nigeria } \\
\text { Job design; work organization Trinidad \& Tobago }\end{array}$ \\
\hline & $\begin{array}{l}\text { Work load/ } \\
\text { demands }\end{array}$ & $\begin{array}{l}\text { Quality of work decreases because often one person needs assume the work on top of their } \\
\text { own work. Namibia } \\
\text { When demands are too high and I cannot do the job then I feel stressed. Albania }\end{array}$ \\
\hline & $\begin{array}{l}\text { Work-home } \\
\text { interface }\end{array}$ & $\begin{array}{l}\text { There is increased transport and more time needed to get to work, hence less leisure time. } \\
\text { Malaysia } \\
\text { You cannot divorce effects of stress from home and work. Namibia }\end{array}$ \\
\hline \multirow[t]{3}{*}{ Work schedule } & Hours worked & $\begin{array}{l}\text { Misusing employees for working longer hours..... Namibia } \\
\text {...or the way that work is organized like long hours. Viet Nam }\end{array}$ \\
\hline & $\begin{array}{l}\text { Time } \\
\text { constraints/ } \\
\text { speed }\end{array}$ & $\begin{array}{l}\text {...need for resources, cannot complete tasks, time constraints, pressure to complete } \\
\text { Puerto Rico } \\
\text {... high speed of work....Thailand }\end{array}$ \\
\hline & Shiftwork & Shiftwork Macedonia, China, Viet Nam, Chile ... \\
\hline \multirow[t]{2}{*}{$\begin{array}{l}\text { Workplace } \\
\text { safety/hazards }\end{array}$} & $\begin{array}{l}\text { Physical/ } \\
\text { physiological } \\
\text { hazards }\end{array}$ & $\begin{array}{l}\text {... mines, the heat, underground. There is heat stress. ...physical environment, ... } \\
\text { Namibia } \\
\text { Unsafe workplace; darkness creates people get eye problems, etc, or bad ventilation ... } \\
\text { Zambia }\end{array}$ \\
\hline & $\begin{array}{l}\text { Working } \\
\text { environment } \\
\text { (poor) }\end{array}$ & $\begin{array}{l}\text { Hazards are there if there are poor interventions and a poor working environment, poor } \\
\text { performance assessment structures and criteria or these are not clear to the worker, in } \\
\text { terms of payment . The environment is not conducive for people to thrive. Zambia } \\
\text { The psychosocial and physical environment is important. It is stress related to the } \\
\text { organization of work and activities, the people, the surroundings, ambiance. Malaysia }\end{array}$ \\
\hline \multirow[t]{4}{*}{ Relationships } & $\begin{array}{l}\text { Psychological } \\
\text { violence }\end{array}$ & $\begin{array}{l}\text { At organizational level this is for example violence at work, such as intimidation. } \\
\text { Namibia } \\
\text { Harassment at work can act as psychosocial hazards. Viet Nam }\end{array}$ \\
\hline & $\begin{array}{l}\text { Physical } \\
\text { violence }\end{array}$ & $\begin{array}{l}\text { Physical violence Trinidad \& Tobago } \\
\text { Harm on the individual in the workplace. Nigeria }\end{array}$ \\
\hline & $\begin{array}{l}\text { Relationships/ } \\
\text { interpersonal } \\
\text { conflict }\end{array}$ & $\begin{array}{l}\text { A hazard emerging from social relations mostly between employers and employees... } \\
\text { Chile } \\
\text { It is the working environment that affects the relationship between workers and managers. } \\
\text { Thailand }\end{array}$ \\
\hline & Support (lack of) & No support Zambia, Macedonia, Thailand, China, Puerto Rico, Pakistan \\
\hline \multirow[t]{2}{*}{$\begin{array}{l}\text { Socio-economic } \\
\text { conflict/ } \\
\text { conditions }\end{array}$} & $\begin{array}{l}\text { War, crime, } \\
\text { poverty }\end{array}$ & $\begin{array}{l}\text {... in the social life of the people in Albania as a result of social change, transition, poverty, } \\
\text { every worker has many problems. When a person has many problems at once and cannot } \\
\text { organize one's life (reference to war, desolation, unemployment). Albania } \\
\text { The impact of psychosocial hazards has larger negative implications in the community } \\
\text { (increased crime rate)... India }\end{array}$ \\
\hline & $\begin{array}{l}\text { HIV/AIDS } \\
\text { (absenteeism) }\end{array}$ & $\begin{array}{l}\text { This (assuming others' work) is particularly the case with HIV/AIDS patients who have } \\
\text { high absence rates. Psychosocial problems, such as ... HIV/AIDS, ... hinder from being } \\
\text { productive at work. ... Namibia } \\
\text { HIV/AIDS problems if there is no programme for workers. Zambia }\end{array}$ \\
\hline
\end{tabular}


Table 4. continued

\begin{tabular}{|c|c|c|}
\hline & $\begin{array}{l}\text { Job security \& } \\
\text { unemployment }\end{array}$ & $\begin{array}{l}\text { There is no continuity, no job security. Very high unemployment, close to } 30 \% \text {, although } \\
\text { official numbers say } 15 \% \text {. Iran } \\
\text { Country is in transition. The social and political system has changed. There is a high rate } \\
\text { of unemployment. ...Macedonia }\end{array}$ \\
\hline & $\begin{array}{l}\text { Social, political, } \\
\text { economic, } \\
\text { cultural, } \\
\text { religious } \\
\text { structures } \\
\text { (existing \& } \\
\text { changing) }\end{array}$ & $\begin{array}{l}\text { People in India have a high tolerance and abilities, and their expectations and aspirations } \\
\text { are low. These problems have just started to emerge. India is trying to adapt. There are } \\
\text { variables in social, economic, financial, and religious spheres that can have an impact on } \\
\text { stress. India } \\
\ldots \text { the culture in my country socializes people to be strong, that is not to show any } \\
\text { weakness, and to cope and not to get overwhelmed. Often issues, ... are ignored due to the } \\
\text { expectations of society. There is not the social system to accommodate these changes, } \\
\text { which result in breakdown of social unit and family. Is any situation or condition that puts } \\
\text { a worker at risk and which is deterioration of social systems... F.S. of Micronesia }\end{array}$ \\
\hline & $\begin{array}{l}\text { Globalization } \\
\text { (market } \\
\text { competition, } \\
\text { multi-nationals, } \\
\text { delocalization of } \\
\text { companies) }\end{array}$ & $\begin{array}{l}\text { Multi-national companies are exonerated of taxes; they produce for export and cannot sell } \\
\text { in Tunisia. We see delocalisations of European companies in Tunisia. Tunisia } \\
\text { The economic boom has resulted in increased work pressure and the development of a } \\
\text { certain ("workaholic") culture. India }\end{array}$ \\
\hline $\begin{array}{l}\text { Concerns for } \\
\text { workers' health }\end{array}$ & Yes & $100 \%$ positive answers by all respondents \\
\hline
\end{tabular}

participants understood time pressure and job demands as psychosocial risks to workers.

- Discrepancies between abilities, skills, job demands and expectations are headed by the EasternMediterranean sample (80\%). These psychosocial risks are understood by all participants, but to a much lesser extent by the Western-Pacific sample (16\%).

- Poor management practices: The Western-Pacific sample most strongly understood this issue as a psychosocial risk to workers $(100 \%)$. To a decreasing extent, these risks are also understood by the Americas, South-East Asia, Europe, the Eastern-Mediterranean and to a lesser extent the African experts.

- Poor physical conditions are part of the array of psychosocial risks for all but African participants. This is particularly the case by Europeans (58\%) and Western-Pacific participants (50\%).

- Lack of participation in decision-making is mostly understood as a psychosocial risk by EasternMediterranean (80\%) followed by South-East Asian (70\%) and European participants (58\%).

- Job insecurity: African participants all agree that this is a psychosocial risk (100\%). South-East Asian followed by Western-Pacific participants also do to a lesser extent (70 and $66 \%$ respectively).
- Precarious employment: All regions understand this as a priority psychosocial risk, headed by Europeans (50\%), and followed by Africa (32\%), and the WesternPacific (32\%).

- Conflict in interpersonal relationships: Participants from all regions understand this as a psychosocial risk, but mostly the Eastern-Mediterranean (60\%) followed by the Western-Pacific participants (50\%).

- Perceived imbalance between abilities, resources and support: Except the Western-Pacific participants, all other participants perceive these as psychosocial risks to a close extent.

\section{Workplace issues that require urgent attention}

Work-related stress: African participants most strongly perceived this emerging hazard as one that needs urgent attention $(100 \%)$. They are closely followed by SouthEast Asian participants in this opinion, and least by Western-Pacific participants (32\%).

- Violence and harassment at work: All regions see these risks as important headed by the Eastern-Mediterranean participants $(80 \%)$. The Africans perceive this as the least important issue to be addressed by all regions (32\%).

- Psychosocial risks: Here also all regions feel that these are important to address, mostly the Americas (88\%), 


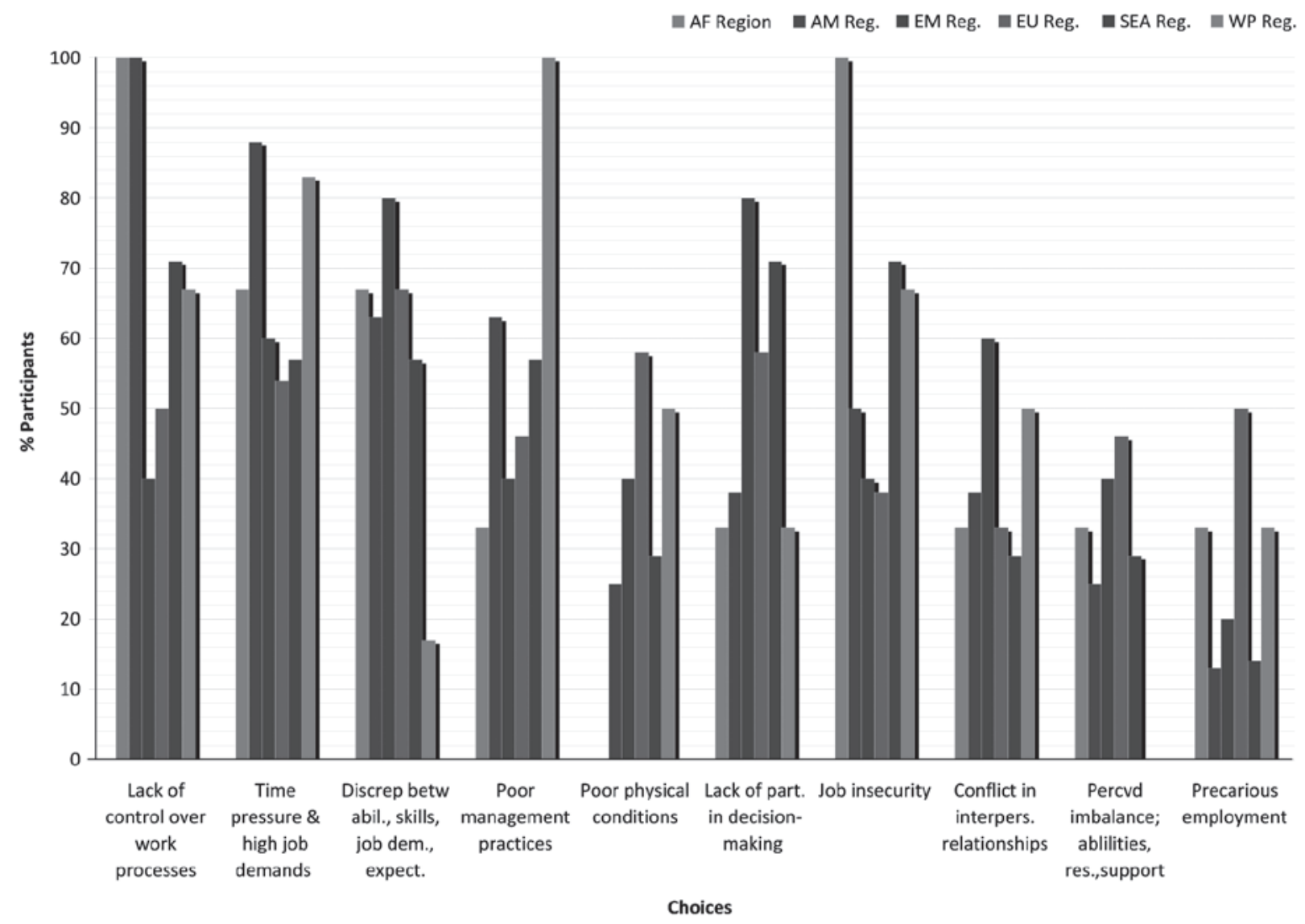

Fig. 1. Delphi results for the understanding of the term psychosocial risk(s).

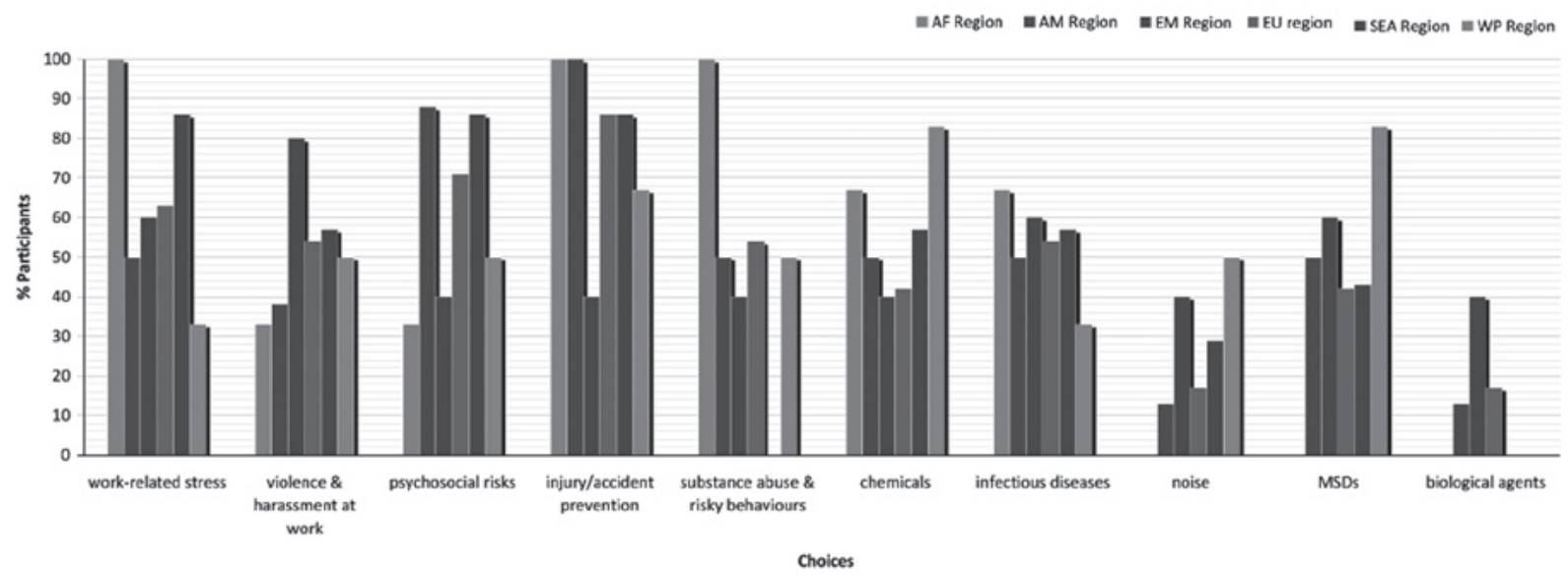

Fig. 2. Delphi results for workplace issues and risks that require urgent attention in developing countries.

followed by the South-East Asian (86\%), and Europeans $(70 \%)$. Africans feel this to a lesser extent $(32 \%)$ than the others.

- Injury and accident prevention: These are the most important issues to be addressed by the Africans (100\%) and the participants from the Americas (100\%). To $86 \%$ the Europeans and South-East Asians are of the same opinion followed by the Western-Pacific (66\%) and lastly, the Eastern-Mediterranean experts (40\%).

- Substance abuse and risky behaviors: For African these 
issues are high importance to address (100\%). All other regions see these issues only as half as important.

- Chemicals: These risks are important for all regions headed by the Western-Pacific (82\%) and followed by the African experts' opinion (66\%).

- Infectious diseases: These are also important for all regions, closely overarched by the African region (66\%).

- Noise: This is an issue of importance to address for all regions but Africa. Mostly by the Western-Pacific region $(50 \%)$ followed by the Eastern-Mediterranean expert opinions $(16 \%)$.

- Musculo-skeletal disorders: These have higher importance for all regions than noise, but lack the opinions of the African experts. The Western-Pacific experts see this issue important by $82 \%$ and the EasternMediterranean participants by $60 \%$.

- Biological agents: Only the Americas (12\%), EasternMediterranean (40\%), and European experts (18\%) see biological agents as an issue that needs to be addressed urgently.

\section{Discussion}

The world, and especially the world of work, has changed. It is increasingly globalized and professionals should capture the tremendous opportunities for bringing multi-disciplinary expertise to developing countries to exchange information and support the development of adequate interventions. This is especially important, if workplace hazards, and in particular new and emerging risks such as those related to the psychosocial working environment, can be addressed at the same time as other workplace risks to have a preventive effect by integrating psychosocial risks into comprehensive occupational health and safety frameworks.

Generally, the knowledge collected through the interviews and the Delphi surveys portraits well the current literature from industrialized countries, but themes in Table 4 go beyond these, whereas Fig. 1 stays close to our understanding of contemporary psychosocial risk pertaining to work content and context and representing stress-related hazards ${ }^{10}$.

Issues that go beyond, address the inclusion of socioeconomic conflict and prevailing conditions in some developing countries. For examples HIV/AIDS is an important issue for particularly the workforce in many African countries. The samples of the interviews and the Delphi surveys are congruent for the African continent in this issue. Due to recent discussions about the brain drain from developing to industrialized countries, a WHO report (2004) reiterates the problems healthcare workers face ${ }^{21)}$. The research studied the migration patterns of health professionals in six countries in Africa. Healthcare workers leave due to unfavorable macroeconomic conditions, physical strain, and low pay including stressful working conditions. For example, the prevalence of HIV/ AIDS is high in Africa. South Africa (57.5\%), Uganda (61.5\%), and Zimbabwe (58.4\%) are among the countries with the highest prevalence. Reasons for leaving included having to deal with dying patients. Healthcare workers reported that they find it stressful to care for HIV patients, and the stresses caused by handling several HIV/AIDSrelated deaths every day takes its toll on nurses, many of whose colleagues also suffer from the disease ${ }^{22}$.

Threats of job insecurity and precarious employment go beyond the African region, but the former are mainly evoked by African participants who saw job insecurity as a psychosocial risk. Both have shown to have the potential to lead to poverty and ill health ${ }^{23,24)}$. Poverty and economic insecurity, in turn, have multiple effects on exposure and vulnerability, mediated by housing, working conditions, and access to nutrition and education ${ }^{25)}$, hence affecting all spheres of a person's life. Poverty may also increase the likelihood of other illnesses, which further increase the vulnerability of workers in developing countries ${ }^{26}$. Research on self-reported job insecurity and workplace closure presents consistent evidence that they have significant adverse effects on self-reported physical and mental health ${ }^{27}$. These results are supported by the known effects of globalization and the emergence of new and insecure sectors and working arrangements, which have become a global phenomenon ${ }^{(\text {e.g., }} 8$.

Figure 1 further outlines the importance of time pressure, high demands, lack of participation in decision-making, lack of support and resources, and discrepancies in expectations ${ }^{11)}$. A perceived imbalance between workers' abilities, available resources and support has been confirmed by the literature as prevalent psychosocial risks ${ }^{(e . g ., 3,28,29)}$. These are discussed in-depth in the Control-SupportDemand ${ }^{11)}$ and Effort-Reward-Balance ${ }^{12)}$.

The workplace issues and risks that require urgent attention in developing countries (Fig. 2), indicate injury and accident prevention as important issues, as well as the accumulation of psychosocial risks including violence and harassment at work, and work-related stress. Global statistics confirm that in a total population of 2.7 billion workers in the world, there are about two million deaths per year that are due to occupational diseases and injuries ${ }^{31)}$. Estimates indicate that the risk for fatal accidents may also be 10-20 times higher in the newly industrialized and developing countries than in the industrialized countries $^{32)}$.

Following the importance of addressing injury and accident prevention, needs were identified by participants for addressing psychosocial risks, work-related stress and violence and harassment at work. According to the Fourth European Working Conditions survey $(2007)^{8)}, 6 \%$ of the workforce was exposed to threats of physical violence, $4 \%$ to violence by other people and 5\% to bullying and/ or harassment at work over the past 12 mon. Psychosocial 
risk factors have been identified as one of the major contemporary challenges for occupational health and safety, which can prove hazardous to employees' health through their perceptions and experience ${ }^{9)}$.

Musculo-skeletal disorders were also identified as a priority issues, with particular emphasis on the WesternPacific region. A dramatic increase in work-related musculo-skeletal disorders in the Republic of Korea caused by psychosocial factors, awkward working postures and repetitive body movements, has been observed since $2000^{33)}$. Research has shown an increasing risk of workrelated diseases and accidents in Southeast Asian countries which have experienced rapid industrialization ${ }^{34)}$. A recent survey revealed the most often reported work-related symptoms to be muscular pain (shoulder, neck, upper arms and lower extremities) (18.1\%), followed by stress (17.9\%), backache (16.8\%), fatigue $(16.7 \%)$ and headache $(11.2 \%)^{35)}$. Symptoms associated with occupational stress, such as muscular pains and fatigue, are common in the working population and these symptoms are often associated with psychological variables such as anxiety and depression ${ }^{36}$. Furthermore, there is an emerging trend in developing countries in the growth of service industries, which has been associated with an increase in musculoskeletal disorders from repetitive and forceful movements and stress-related diseases ${ }^{37)}$.

Substance abuse and risky behaviors were rated important and with consensus. Alcohol is the most commonly used substance in most regions of the world, although prevalence varies. It is a major contributor to the burden of disease, accounting for $1.5 \%$ of all deaths and $3.5 \%$ of the total disability adjusted life years ${ }^{38)}$. Economic stress, such as high unemployment, within a community may induce "maladaptive" coping behaviors, such as smoking and alcohol use ${ }^{32}$. Labonte and Schecker $(2006)^{39)}$ specify that economic stress may exacerbate tensions between social groups, magnify workplace stressors. For example some recent events in the African region, South-Africa, Zimbabwe, Rwanda, Burundi, and Uganda to name a few, provide some empirical evidence for increase in tensions between social groups, also beyond the workplace, and the high prevalence in risky behaviors with respect to HIV/AIDS infections for example. The latter is also evidenced by the WHO migration report $(2004)^{21)}$.

Notably, there are stark differences in the workplace environment and standards in the developing world ${ }^{40)}$. Generally, legislation, policy and standards development need addressing and/or improving, and so do employment and working conditions. Awareness raising and education are key to achieving impact. Interestingly, these issues still represent priorities in industrialized countries too ${ }^{41)}$, possibly at a different level though.

Nuwayhid (2004) ${ }^{42)}$ argues that the internal domain of occupational health research, such as focusing on workplace hazards, work organization, exposure-disease spectrum, etc., works well in industrialized countries, but that it does not translate well to developing countries due to the lack of mechanisms and risk assessment processes. In addition, inadequate social and technical infrastructure in developing countries pose a problem for tackling existing and new occupational hazards efficiently, as the situation on work-related injuries and diseases confirms $^{30)}$.

Nevertheless, it would appear that the consensus obtained on the importance of psychosocial hazards at work is indicative of the necessity to address these emerging issues beyond industrialized contexts. The complex relationships between macro-economic issues, working conditions, workers' health, as well as health behaviors, clearly point to the need for an intervention model that addresses workplace and contextual issues in a comprehensive manner. Time seems ripe to address these needs caused by the ever-changing nature of work and its contexts within the limits of developing country contexts, and in the first instance, in particular, through increased research. Research will form the basis for policy development and prepare the ground to go beyond the traditional focus and to include psychosocial workplace risk.

Some limitations of this research lie in the small and non-randomized sample. Although this research cannot claim representativeness, it is, however, a first-time exploratory attempt to reach multi-disciplinary experts in developing countries and to learn about their views on the different issues. The study response shows increasing interest in the exploration of these emerging issues. As much as psychosocial risks are ill-addressed in many industrialized countries, it is still important to keep the world in our view, as well as the workers in developing countries who are exposed to these new forms of hazards.

\section{References}

1) Sen A. Global Doubts. Commencement Day Address, Harvard University - June 8th, 2000. [Online]. 2000 [cited 2010 Oct 12]; Available from: URL: http://www. commencement.harvard.edu/2000/sen.html

2) World Health Organization. Final Report of the Commission on Social Determinants for Health. Employment conditions knowledge network (EMCONET). 2007.

3) Houtman I, Jettinghoff K, Cedillo L. Raising awareness of stress at work in developing countries - a modern hazard in a traditional working environment. Geneva: World Health Organization; (Protecting Workers' Health series no. 6) 2008.

4) Rosenstock L, Cullen MR, Fingerhut MA. Disease Control Priorities in Developing Countries. J Occup Health 2006; 1127-45.

5) World Health Organization. Global Strategy on 
Occupational Health for all. The way to health at work. [Online]. 1995 [cited 2008 Jul 12]; Available from: URL: http://www.who.int/occupational_health/ globstrategy/en

6) Cox T, Griffiths A, Rial-González E. Research on workrelated stress. European Agency for Safety \& Health at Work. Luxembourg: Office for Official Publications of the European Communities; 2000.

7) Idris M, Dollard M, Winefield AH. Lay theory explanation of occupational stress: the Malaysian context. Cross Cultural Management: an International Journal 2010; 135-53.

8) EU-OSHA - European Agency for Safety and Health at Work. Expert forecast on emerging psychosocial risks related to occupational safety and health. FACTS. 74EN. Belgium. 2007.

9) Cox T, Rial-Gonzalez E. Work-related stress: the European picture. Working on stress. Magazine of the European Agency for Safety and Health at Work 2002: $5 ; 4-6$.

10) Leka S, Griffiths A, Cox T. Protecting Workers' Health series no. 3. Work Organisation and Stress: for employers, managers and trade unions representatives. Geneva: World Health Organisation; 2004.

11) Karasek RA, Theorell T. Healthy Work, Stress, Productivity, and the Reconstruction of Working Life. NY: Basic Books; 1990.

12) Siegrist J. Adverse health effects of high-effort/lowreward conditions. J Occup Health Psychol 1996;1: 27-41.

13) Stansfeld S, Candy B. Psychosocial work environment and mental health - a meta-analytic review. Scand J Work Environ Health 2006; 32: 443-62.

14) Siegrist J, Marmot M. Health inequalities and the psychosocial environment-two scientific challenges. Social Science and Medicine 2004; 58:1463-73.

15) Juarez- Garcia A, Schnall P L. Psychosocial factors and work stress research in Mexico: A new Latin- American Network. GOHNET Newsletter. WHO. [Online] 2007. [cited 2009 May 29]; Available from: URL: http://www. who.int/occupational_health/publications/newsletter/ en/index.html

16) First Interministerial Conference on Health. New and emerging environmental threats to human health. Executive Summary. [Online]. 2008 [cited 2008 Aug 29]; . Available from: URL: http://www.unep.org/healthenv/pdfs/TD-New-and-emerging-threats.pdf

17) Miles MB, Huberman AM. Qualitative Data Analysis. Sage Publications 1994; 2nd edition.

18) Delbecq Van de Ven, Gustafson P. Group techniques for program planning: a guide to nominal group and Delphi processes. Scott, Foresman (Glenview, III.); 1975. p. 10 .

19) Turoff M, Hiltz SR. Computer Based Delphi Processes. Gazing Into the Oracle: The Delphi Method and Its Application to Social Policy and Public Health. London: Kingsley Publishers; 1996.

20) Braun V, Clarke V. Using thematic analysis in psychology. Qualitative research in psychology 2006; 3: 77-101.
21) World Health Organization. Regional Office for Africa, Brazzaville. Migration of health professionals in six countries: a synthesis report. 2004.

22) Stillwell B. Healthworker motivation in Zimbabwe. Internal report for the Department of Organization and Healthcare Delivery. WHO Bulletin 2001. 82, 8, 2004, 559-636. Geneva: World Health Organization.

23) Semmer NK. Job stress interventions and the organization of work. Scandinavian Journal of Work, Environment and Health 2006; 32: 515-27.

24) Vahtera J, Kivimaki M, Pentti J, et al. Organisational downsizing, sickness absence, and mortality: 10-town prospective cohort study. BMJ 2004; 328: 555.

25) Labonte R, Schrecker T. Globalization and social determinants of health: analytic and strategic review paper. 2006.

26) Benach J, Muntaner C, Santana V. Employment conditions and health inequalities: Final report to the WHO Commission on Social Determinants of Health. Geneva:WHO; 2007.

27) Marmot M, Ferrie J, Newman K, Stansfield S. The contribution of job insecurity to socioeconomic inequalities. Research Findings: 11. Health Variations Programme. 2001.

28) EU-OSHA - European Agency for Safety and Health at Work. Expert forecast on emerging psychosocial risks related to occupational safety and health. European Risk Observatory Report. 2007.

29) Sanderson K, Andrews G. Common mental disorders in the workforce: recent findings from descriptive and social epidemiology. Canadian Journal of Psychiatry 2006; 51: 63-75.

30) Morris L. The process of decision-making by stressed social workers: to stay or leave the workplace. International Review of Psychiatry 2005; 17: 347-54.

31) Takala J. Life and health are fundamental rights for workers (interview). Labour Education 2002; 1:1-7.

32) Takala J. Global estimates of fatal occupational accidents. In: $16^{\text {th }}$ International Conference of Labour Statistics, Geneva. ILO; 1998. Geneva.

33) Park J. National Strategies for Job Stress Management in Korea (p. 69). In Abstracts Second ICOH. international conference on psychosocial factors at work: Job stress prevention in a global perspective; August 23-26, 2005 in Okayama, Japan. ICOH/WOPS.

34) Haratani T, Kawakami N. Organization of work in a global economy. Work, Stress and Health Conference. Baltimore Convention Center, March 11-13 1999.

35) Park J, Lee N. First Korean Working Conditions Survey: a comparison between South Korea and EU Countries. Industrial Health 2009; 47: 50-4.

36) Satzer R. Zur ganzheitlichen Gefährdungsbeurteilung gehören psychische Belastungen, BAUA-Daten: ND: 061132, SO: Gute Arbeit 2008; CN: ZS0845 IM: 20, Nr. 3, S. 32-33 (Abb.)

37) Wegman DH. Aging and globalization. Med Lav 2006; 97: $137-42$.

38) The World Health Report 2001. Geneva: World Health Organization.

39) Labonte R, Schrecker T. Globalization and social 
determination of health: analytic and strategic review paper. On behalf of the Globalization Knowledge Network 2006.

40) Chopra P. Mental health and the workplace: issues for developing countries. International Journal of Mental Health Systems 3. 2009. p. 1-9.

41) The European Framework for Psychosocial Risk
Management: PRIMA-EF. Edited by Stavroula Leka and Tom Cox. Institute of Work, Health and Organisations. 2008.

42) Nuwayhid IA. Occupational Health Research in Developing Countries: a Partner for Social Justice. Am J Public Health 2004; 94: 1996-21. 